\title{
Custo-efetividade do cateterismo venoso central guiado por ultrassonografia no Sistema Único de Saúde - SUS
}

\author{
Carlos Eduardo Pessanha BOLLER ${ }^{(1)}$ \\ Kátia Marie Simões SENNA ${ }^{(1)}$ \\ Marcelo Correa GOULART ${ }^{(1)}$ \\ Bernardo Rangel TURA ${ }^{(1)}$ \\ Marisa da Silva SANTOS ${ }^{(1)}$
}

Recebido: 28 jan 2019 Aceito: 10 fev 2019

Autor de correspondência: kadu.boller@gmail.com

Conflito de interesses: Os autores declaram não haver nenhum interesse profissional ou pessoal que possa gerar conflito de interesses em relação a este manuscrito.

(1)Instituto Fernandes Figueira, Fundação Oswaldo Cruz - Fiocruz, Rio de Janeiro, RJ, Brasil.

\section{Resumo}

O cateterismo venoso central é um procedimento utilizado com frequência nas Unidades de Terapia Intensiva e consiste na inserção de um dispositivo por meio da rede venosa e posicionamento na veia cava. Estima-se que seja realizado cerca de cinco milhões por ano, $15 \%$ destes acarretam em complicações e, se necessário uma segunda tentativa, o risco de suceder danos é potencializado em 5,5 vezes. O pneumotórax e a punção arterial acidental são suas principais complicações quando realizado em veia subclávia e veia jugular interna, respectivamente, podendo ter associação com variações anatômicas, alterações fisiológicas ou treinamento insuficiente. A ultrassonografia vem sendo utilizada como auxiliar no cateterismo venoso central com o objetivo de minimizar riscos e reduzir complicações, porém essa técnica ainda não é universalmente adotada em virtude de limitações financeiras. Em um cenário marcado por recursos escassos é primordial ponderar o custo de agregar a tecnologia ao procedimento mediante a sua capacidade de reduzir complicações e falhas. A adoção de um limiar que determina se uma tecnologia deve ser ou não considerada custoefetiva, e consequentemente viável à incorporação, é motivo de debate na literatura e entre gestores da área da saúde, porém sua existência proporcionaria, teoricamente, vantagens como a redução da carga de responsabilidade daqueles que tomam as decisões, gerando maior transparência e confiança no processo. Apesar de cada País possuir autonomia para definir (ou não) esse valor, poucos países das Américas (do Norte, Central e do Sul) possuem limiares estabelecidos e o Brasil não está incluído nesta lista, apesar de exigir análises de custoefetividade como requisito para a incorporação. Existem diversos tipos de avaliações econômicas devendo ser analisado qual a mais indicada, de acordo com a relação que se deseja construir entre os custos e os resultados da estratégia terapêutica. O presente estudo objetivou elaborar uma avaliação econômica de custo-efetividade da técnica de cateterismo venoso central quando guiada pelo ultrassom comparando-a técnica padrão orientada somente pelos 
marcos anatômicos, realizada em adultos, sob a perspectiva do Sistema Único de Saúde brasileiro. Foi estruturado um modelo econômico de árvore de decisão no software TreeAgeProem função dos desfechos serem de curto prazo não necessitando da realização de ciclos em um cenário fictício uma unidade de atendimento terciário de saúde, na qual o ultrassom havia sido adquirido anteriormente e os profissionais estavam sem nenhum treinamento prévio para a realização do procedimento. Verificou-se por meio de uma busca estruturada na literatura (base de dados MEDLINE via PubMed) os dados de prevalência para a construção do modelo econômico, sumarizando-os por meio de meta-análises. Utilizou-se como horizonte temporal, o período de três dias após a realização do procedimento, haja vista que segundo o painel de especialistas é o tempo necessário para diagnóstico e tratamento das potenciais complicações. Em virtude deste curto horizonte temporal, não foi adotada nenhuma taxa de desconto na avaliação econômica. Por fim, optou-se por selecionar como desfechos a ocorrência ou não da punção acidental grave (quando analisada veia jugular interna) e pneumotórax (quando veia subclávia), dado a sua relevância evidenciada pelas informações disponíveis na literatura. Os custos diretos estimados para os materiais e procedimentos foram valorados utilizando bancos de registros de compras nacionais. Foi adotado uma intenção de pagar no valor de $R \$ 18.125,00$ baseado na curva de aceitabilidade do procedimento. Realizada análise de sensibilidade determinística com parâmetros de variação de $50 \%$ do valor da média como limites superior e inferior, e para análise probabilística o mesmo intervalo de valores realizando 1.000 simulações de Monte Carlo. A variação em questão foi escolhida por proporcionar uma faixa mais abrangente e assim obter o real impacto das variáveis. No restante, menciona-se que na análise probabilística os valores das efetividades foram simulados utilizando uma distribuição beta e os do custo uma distribuição gama. A razão do custoefetividade incremental para a ultrassonografia no sítio veia jugular interna foi de R\$14.922,34 para cada complicação grave evitada. Após a realização da análise probabilística identificou-se que $63,6 \%$ das simulações foram custo-efetivas e apenas $8,9 \%$ não foram efetivas em relação à técnica padrão. No sítio veia subclávia, a razão de custo-efetividade incremental estimada para a ultrassonografia foi de $\mathrm{R} \$ 15.346,39$ por complicação grave evitada. Após a realização da análise probabilística, identificou-se que $80,1 \%$ das simulações foram custo-efetivas, sendo $13,2 \%$ destas dominantes. O exercício da medicina está cada vez mais apoiado em tecnologias que supostamente viabilizam tomadas de decisões e realização de procedimentos de forma mais eficaz, porém nem sempre a tecnologia alcança comprovadamente seu objetivo e em poucas vezes existe vantagem do ponto de vista econômico. Todo procedimento possui custos diretos associados não só a sua realização, como a correção das possíveis complicações produzidas. Este estudo identificou que a tecnologia estudada onera o procedimento não só pela necessidade de treinamento da equipe, mas também pela utilização da capa protetora, uma vez que deve ser realizado sob técnica estéril. A intervenção estudada mostrou-se eficaz e segura. Considerando 
todos os custos associados, assim como a efetividade de cada procedimento nos sítios analisados, conclui-se que a intervenção avaliada é eficaz, segura e custoefetiva em ambos os sítios, sendo mais custo-efetiva na punção de veia jugular interna.

Descritores: Cateterismo Venoso Central; Ultrassonografia de Intervenção; Análise Custo-Efetividade; Tecnologia Biomédica. 